\title{
Current trend and risk factors for kidney stones in persons with spinal cord injury: a longitudinal study
}

\author{
Y Chen ${ }^{*}, 1$, MJ DeVivo' ${ }^{1}$ and JM Roseman ${ }^{2}$ \\ ${ }^{1}$ Department of Physical Medicine and Rehabilitation, University of Alabama at Birmingham, Birmingham, Alabama, \\ USA; ${ }^{2}$ Department of Epidemiology, School of Public Health, University of Alabama at Birmingham, Birmingham, \\ Alabama, USA
}

\begin{abstract}
Study design: A multi-center longitudinal study.
Objectives: To estimate the current trend in the incidence of first kidney stone among persons with spinal cord injury (SCI) and to delineate the potential contributing factors.

Setting: Twenty-one Model SCI Care Systems throughout the United States.

Methods: A longitudinal cohort of 8314 subjects enrolled in the National SCI Database between 1986 and 1999 was used to estimate and compare the incidence of first kidney stone with a previous report of 5850 SCI patients injured between 1973 and 1982. A Cox regression analysis was performed to identify risk factors for stones, including age, race, gender, severity of injury, and method of urinary drainage. These variables have been routinely collected, on a yearly basis, by the collaborating SCI centers.

Results: During the 12 years, 6 months of case ascertainment, 286 incident stone cases were documented. The risk was greatest during the first 3 months after injury ( 31 cases per 1000 person-years), quickly decreasing and leveling off later (eight cases per 1000 person-years). It was estimated that within 10 years after injury, $7 \%$ of persons with SCI would develop their first kidney stone. There was no evidence that the risk has changed over the past 25 years $(P=0.96)$. During the first year post injury only, a significantly increased risk of stones was observed in Caucasians and persons aged 45 years or older. A positive association of the severity of injury and requiring instrumentation for bladder emptying with kidney stones was found after the first year post injury. The type of urinary drainage, including indwelling, intermittent, and condom catheterization, had no significant differential effect on stone formation at either risk period.

Conclusions: The highest risk of kidney stones is within the first few months post injury. Little progress has been made in reducing this risk. Although inability to control bladder function is an important risk factor after the first year post injury, for those who need bladder management, the type of urinary drainage does not appear to be an important factor in determining risk.
\end{abstract}

Spinal Cord (2000) 38, 346-353

Keywords: spinal cord injury; calculi; nephrolithiasis; epidemiology

\section{Introduction}

Injury to the spinal cord can result in impairment of sensory, motor, and autonomic function. This primarily neurologic lesion coupled with associated problems such as immobilization, metabolic alteration, and neurogenic bladder and bowel dysfunction, predispose people with spinal cord injury (SCI) to a variety of secondary complications for the remainder of their lives.

Urinary stones, primarily struvite (magnesium ammonium phosphate), ${ }^{1,2}$ have long been considered as one of the most common urologic complications in

*Correspondence: Y Chen, Department of Physical Medicine and Rehabilitation, Spinal Rehabilitation Center, Room 548, 1717 6th Avenue South, Birmingham AL 35233, USA the SCI population. ${ }^{3-7}$ In our previous report in 1984 , we estimated that approximately $8 \%$ of SCI patients would develop kidney stones within 8 years after injury. ${ }^{5}$ The risk of kidney stones was highest during the first 3 months post injury, quickly decreasing and leveling off after a year. Since 1984, however, very few studies have been conducted prospectively to examine the current trend and determinants of this serious medical complication following cord injury.

Past studies have reported SCI stone formers to be older, ${ }^{8}$ to have a neurologically complete lesion, ${ }^{3-5}$ and to use a catheter for urinary drainage. ${ }^{9-11}$ However, limited conclusions can be drawn from previous investigations, particularly regarding the 
causal role of bladder management. Because people with SCI tend to change methods, using information obtained at admission and discharge ${ }^{5}$ may become inaccurate. Similarly, using data obtained at/after stone onset ${ }^{8-10}$ makes interpretation uncertain whether a stone disease is a consequence or a cause of a particular bladder management.

The present study analyzed data from an on-going multi-center longitudinal study of natural history following SCI to explore the current nephrolithiasis risk and time-variant contributing factors by use of Cox regression analysis.

\section{Methods}

\section{Study population}

The National SCI Database contains standardized data contributed by all federally funded Model SCI Care Systems since 1973. Data have been collected on sociodemographic characteristics, injury-related information, medical complications, and functional status of all eligible subjects at admission to and discharge from the Model Systems, as well as annually thereafter. The inclusion and exclusion criteria, data collection process, quality control, and collaborating centers of the database have been previously described in detail. ${ }^{12}$ For the present study, we limited the analyses to participants enrolled in the database between October 1, 1986, and March 31, 1999, aged 15-80 years at injury, and discharged alive from initial hospital care.

\section{Data collection}

Incident cases were defined as those participants who had an abnormal concretion in either the kidney or ureter documented by X-ray evidence of its location. Stones originating in the bladder or stones that were passed spontaneously before X-ray evidence could be obtained were excluded. Only stones documented as first occurrences at discharge or annual examination were included. As the exact time of stone diagnosis was not documented in the database, we arbitrarily assigned event date as the midpoint between the last negative report and the present positive finding. If incident cases were reported on the hospital discharge summary, the event date was assigned as the midpoint of the period between injury and discharge; if reported at the year 1 visit, it was assigned as the midpoint between discharge and the first anniversary date; otherwise, it was assigned as the midpoint during the anniversary year when stones were reported.

The duration of staying free of stones for each participant was counted from the date of injury to the date of stone diagnosis or last contact, whichever came first. If participants missed three or more consecutive annual visits, they were considered as lost to the system. The date of last examination before loss, death, or termination of study was defined as last contact.
Information on demographics and severity of injury was obtained at enrolment, whereas data on method of bladder drainage were collected on a yearly basis. To account for the time-variant nature of bladder management, information obtained at the previous visit was considered as the method of urinary drainage corresponding to the formation of stones.

\section{Statistical analysis}

A standard life-table method was performed to estimate current trend in the hazard and cumulative incidence of kidney stones compared with the previous report of SCI patients enrolled in the database between 1973 and 1982. ${ }^{5}$ We used log-rank test to examine the statistical significance of differences in stone-free survivorship between cohorts, genders, races, levels of neurologic impairment, age at injury, and bladder management at discharge.

Cox regression analysis has been considered as one of the standard methods for longitudinal data with interval censoring and time-dependent covariates. ${ }^{13} \mathrm{It}$ requires the least restrictive assumption and is subject to the least residual confounding from a time factor. Therefore, the present analysis applied Cox regression model with time-variant age and bladder management to examine the effects of age, race, gender, severity of injury, and type of urinary drainage on stone formation. The risk ratio (RR) is presented to indicate the magnitude of association and $95 \%$ confidence interval (CI) is used to measure the statistical significance and the precision of risk ratio estimates.

Because the risk of kidney stones has been reported to be highest during the initial period post injury and because it is biologically plausible that early stone formation may have different determinants than later formation, the analyses were stratified by two risk periods: before and after the first year post injury.

\section{Results}

A total of 8314 SCI subjects injured between 1986 and 1999 from 21 Model SCI systems were eligible for the assessment of the hazard and cumulative incidence rates. The characteristics of study subjects are presented in Table 1. Because of the dynamic nature of enrollment in the database and changes in Model System designation (new Systems coming on line; old Systems losing funding and dropping out of the database), the length of follow-up varied by the collaborating SCI centers and participants, ranging from 7 months to 13 years with an average of 3 years. During this study period, 286 stone cases (3\%) were reported. Of the 8028 stone-free subjects, $2664(33 \%)$ were censored as they were lost to follow-up voluntarily or involuntarily because of changes in Model System designation. The rest $(67 \%)$ were censored because of the termination of study or death (Table 2). Overall, among those stone-free participants, 
Table 1 Characteristics of study subjects and corresponding 5-year cumulative incidence (CI) of kidney stones

\begin{tabular}{|c|c|c|c|c|c|}
\hline Characteristics & $\mathrm{n}$ & $\%$ & No. s & $(\%)$ & $\mathrm{P}^{*}$ \\
\hline \multicolumn{6}{|l|}{ Gender } \\
\hline Women & 1536 & $(18.5)$ & 42 & 4.2 & \multirow[t]{2}{*}{0.10} \\
\hline Men & 6778 & $(81.5)$ & 244 & 4.7 & \\
\hline \multicolumn{6}{|l|}{ Race } \\
\hline African American & 2290 & $(27.5)$ & 55 & 3.4 & \multirow[t]{4}{*}{0.0005} \\
\hline Caucasian & 4843 & $(58.3)$ & 205 & 5.6 & \\
\hline Hispanic & 931 & $(11.2)$ & 17 & 2.3 & \\
\hline Other & 250 & $(3.0)$ & 9 & 4.3 & \\
\hline \multicolumn{6}{|l|}{ Age at injury (years) } \\
\hline $15-24$ & 2952 & $(35.5)$ & 116 & 5.1 & \multirow[t]{5}{*}{0.04} \\
\hline $25-34$ & 2189 & (26.3) & 60 & 3.5 & \\
\hline $35-44$ & 1404 & (16.9) & 49 & 5.6 & \\
\hline $45-54$ & 788 & $(9.5)$ & 23 & 3.2 & \\
\hline $55-80$ & 981 & (11.8) & 38 & 5.4 & \\
\hline \multicolumn{6}{|l|}{ Neurologic level } \\
\hline Minimal deficit & 461 & $(5.5)$ & 0 & 0.0 & \multirow[t]{6}{*}{0.0003} \\
\hline Paraplegic, incomplete & 1698 & $(20.4)$ & 49 & 4.2 & \\
\hline Paraplegic, complete & 2318 & $(27.9)$ & 77 & 4.1 & \\
\hline Tetraplegic, incomplete & 2314 & $(27.8)$ & 71 & 4.1 & \\
\hline Tetraplegic, complete & 1508 & $(18.1)$ & 89 & 6.9 & \\
\hline Unknown & 15 & $(0.2)$ & 0 & & \\
\hline \multicolumn{6}{|l|}{ ASIA Grade } \\
\hline A & 3826 & $(46.0)$ & 166 & 5.2 & \multirow[t]{6}{*}{0.03} \\
\hline $\mathrm{B}$ & 864 & $(10.4)$ & 34 & 5.2 & \\
\hline $\mathrm{C}$ & 1159 & (13.9) & 44 & 4.9 & \\
\hline $\mathrm{D}$ & 2402 & $(28.9)$ & 42 & 2.8 & \\
\hline $\mathrm{E}$ & 46 & $(0.6)$ & 0 & 0.0 & \\
\hline Unknown & 17 & $(0.2)$ & 0 & & \\
\hline \multicolumn{6}{|l|}{ Neurologic deficit } \\
\hline Minimal deficit & 461 & $(5.5)$ & 0 & 0.0 & \multirow[t]{5}{*}{$<0.0001$} \\
\hline ASIA Grade D & 1987 & $(23.9)$ & 42 & 3.0 & \\
\hline Paraplegic, ASIA grade $\mathrm{A}, \mathrm{B}$ or $\mathrm{C}$ & 3249 & $(39.1)$ & 108 & 4.3 & \\
\hline Tetraplegic, ASIA grade $\mathrm{A}, \mathrm{B}$ or $\mathrm{C}$ & 2600 & $(31.3)$ & 136 & 6.3 & \\
\hline Unknown & 17 & $(0.2)$ & 0 & & \\
\hline \multicolumn{6}{|l|}{ Bladder management at discharge } \\
\hline Catheter-free & 1710 & $(20.6)$ & 20 & 1.6 & \multirow[t]{7}{*}{0.002} \\
\hline Indwelling urethral catheter & 1027 & (12.4) & 49 & 6.9 & \\
\hline Condom catheter & 563 & $(6.8)$ & 25 & 5.1 & \\
\hline Intermittent catheter & 4407 & $(53.0)$ & 179 & 5.0 & \\
\hline Suprapubic catheter & 296 & $(3.6)$ & 8 & 2.7 & \\
\hline Other & 248 & $(3.0)$ & 5 & 3.4 & \\
\hline Unknown & 63 & $(0.8)$ & 0 & & \\
\hline
\end{tabular}

*Log-rank test

lost to follow-up was more common in men, Hispanics, African Americans, and persons with minimal or incomplete neurologic lesion and better bladder control.

It was estimated by a life table method that within 10 years after injury, $7 \%$ of the present cohort of SCI individuals would develop their first kidney stone. The instantaneous rate (hazard) of stones reached its peak during the first 3 months (31 cases per 1000 personyears) and then leveled off after the first year (eight cases per 1000 person-years) till the 8th year, when it decreased to less than four cases per 1000 person-years (Figure 1). When compared with a previous cohort of
5850 SCI patients that were injured between 1973 and 1982 , the risk of kidney stones seemed to be somewhat consistent over the last 25 years $(P=0.96)$.

The stone-free survivorship was significantly associated with race, age at injury, severity of injury, and method of bladder management at discharge (Table 1). It was estimated that within 5 years after injury, $5 \%$ of male SCIs would develop stones, which was slightly higher than their female counterparts $(4 \% ; P=0.10)$. The 5-year cumulative incidence rate was higher in Caucasians $(6 \%)$ and lower in Hispanics $(2 \%)$ and African Americans $(3 \% ; P<0.001)$. Although the 5year cumulative incidence rate significantly differed 
Table 2 Characteristics of stone-free subjects grouped by the compliance or lost to follow-up programs

\begin{tabular}{|c|c|c|c|c|c|}
\hline \multirow[b]{2}{*}{ Characteristics } & \multicolumn{4}{|c|}{ Compliant participants lost to follow-up } & \multirow[b]{2}{*}{$\mathrm{P}^{*}$} \\
\hline & $\mathrm{n}$ & $\%$ & $\mathrm{n}$ & $\%$ & \\
\hline Total & 5364 & $(66.8)$ & 2664 & $(33.2)$ & \\
\hline $\begin{array}{l}\text { Age at injury } \\
\quad \text { (mean } \pm \text { standard deviation) }\end{array}$ & $34 \pm 15$ & - & $32 \pm 14$ & - & $<0.0001$ \\
\hline \multicolumn{6}{|l|}{ Gender } \\
\hline Women & 1059 & $(70.9)$ & 435 & $(29.1)$ & 0.0002 \\
\hline Men & 4305 & $(65.9)$ & 2229 & $(34.1)$ & \\
\hline \multicolumn{6}{|l|}{ Race } \\
\hline African American & 1387 & $(62.1)$ & 848 & $(37.9)$ & $<0.0001$ \\
\hline Caucasian & 3260 & $(70.3)$ & 1378 & $(29.7)$ & \\
\hline Hispanic & 551 & $(60.3)$ & 363 & $(39.7)$ & \\
\hline Other & 166 & $(68.9)$ & 75 & $(31.1)$ & \\
\hline \multicolumn{6}{|l|}{ Neurologic deficit } \\
\hline Minimal deficit & 142 & $(30.8)$ & 319 & $(69.2)$ & $<0.0001$ \\
\hline ASIA grade D & 1117 & $(57.4)$ & 828 & $(42.6)$ & \\
\hline Paraplegic, ASIA grade A, B, or C & 2225 & $(70.8)$ & 916 & $(29.2)$ & \\
\hline Tetraplegic, ASIA grade $\mathrm{A}, \mathrm{B}$, or $\mathrm{C}$ & 1865 & $(75.7)$ & 599 & $(24.3)$ & \\
\hline Unknown & 15 & $(88.2)$ & 2 & $(11.8)$ & \\
\hline \multicolumn{6}{|l|}{ Bladder management at discharge } \\
\hline Catheter-free & 823 & $(48.7)$ & 867 & $(51.3)$ & $<0.0001$ \\
\hline Indwelling urethral catheter & 757 & (77.4) & 221 & $(22.6)$ & \\
\hline Condom catheter & 351 & $(65.2)$ & 187 & $(34.8)$ & \\
\hline Intermittent catheter & 2994 & $(70.8)$ & 1234 & $(29.2)$ & \\
\hline Suprapublic catheter & 226 & $(78.5)$ & 62 & $(21.5)$ & \\
\hline Other & 165 & $(67.9)$ & 78 & $(32.1)$ & \\
\hline Unknown & 48 & $(76.2)$ & 15 & $(23.8)$ & \\
\hline
\end{tabular}

*Student's $t$-test for age comparison and Chi-square test for other variables.

between age groups at injury $(P=0.04)$, no consistent trend was observed.

Persons with minimal neurologic deficit, which refers to abnormal reflexes or minimal damage without significant or incapacitating loss of neurologic function, remained free of stones for up to 8 years after injury. The risk of kidney stones seemed to be identical for paraplegics, incomplete and complete, and incomplete tetraplegics, with a 5year cumulative incidence of $4 \%$, whereas it was $7 \%$ for complete tetraplegics. There was also no apparent difference in 5-year cumulative incidence between American Spinal Injury Association (ASIA) Impairment Scales $\mathrm{A}, \mathrm{B}$, and $\mathrm{C}$, all around $5 \%$. However, much lower risks for $\mathrm{D}(3 \%)$ and $\mathrm{E}(0 \%)$ were observed. We further classified the severity of injury into four groups: minimal deficit; ASIA grade D; paraplegics with grades $\mathrm{A}, \mathrm{B}$ or $\mathrm{C}$; and tetraplegics with grades A, B, or C. A significant increasing stone risk with an increasing severity of injury was noted $(P<0.001)$.

For persons who could void satisfactorily using any method of reflex stimulation or any form of extrinsic pressure at discharge, less than $2 \%$ were estimated to get stones within 5 years. This figure was much higher for users of indwelling uretheral $(7 \%)$, condom $(5 \%)$, intermittent $(5 \%)$, or suprapubic catheterization $(3 \%)$ at discharge.
In the Cox regression models, we excluded those with minimal neurologic deficit $(n=461)$, unknown neurologic level $(n=17)$, and unknown method of urinary drainage $(n=63)$. Therefore, a total of 7784 subjects was available for the assessment of risk factors for kidney stones diagnosed within a year (inclusive) after injury, whereas 4858 subjects had adequate information for the evaluation of risk factors for kidney stones developed after the first year post injury.

As depicted in Table 3, after potential confounding factors, including method of bladder management, were accounted for, men were approximately 50\% more likely than women to develop stones regardless of the risk period; however the statistical significance was marginal $(P=0.09$ for year $1 ; P=0.19$ for year 2 and later). The higher risk in Caucasians than that in African Americans appeared to be stronger during the first year post injury $(\mathrm{RR}=2.1,95 \% \mathrm{CI}$ : $1.3-3.3)$, as opposed to year 2 and later $(\mathrm{RR}=1.3,95 \% \mathrm{CI}$ : $0.8-$ 1.9). Compared with individuals aged 25 to 34 years, individuals aged 55 years or older had a twofold increased risk during the first year $(\mathrm{RR}=2.0,95 \% \mathrm{CI}$ : $1.1-3.5)$ and a $50 \%$ increased risk later $(\mathrm{RR}=1.5$, 95\% CI: $0.9-2.6)$.

A positive association between kidney stone risk and severity of injury was observed at both risk periods after adjusting for type of urinary drainage. 
However, it appeared to be somewhat stronger in later years. Bladder management had no significant effect on kidney stones that occurred within a year after injury, but played a stronger role during year 2 and later. As compared with those with catheter-free and continent bladder control, users of indwelling urethral or suprapubic catheters, condom catheterization, or

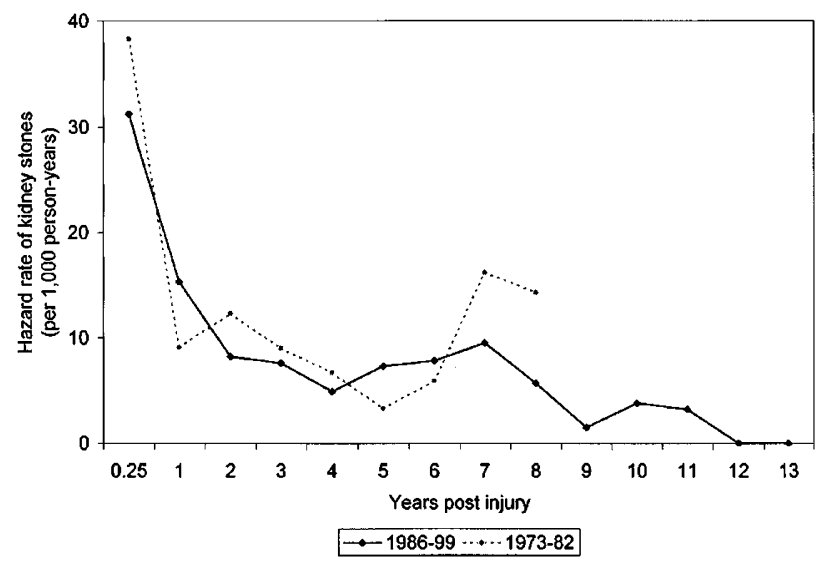

Figure 1 The hazard (instantaneous incidence) rate of kidney stones in persons with spinal cord injury by years post injury intermittent catheterization had more than a twofold increased risk, and persons using other methods for bladder emptying (such as conduit, pyelostomy, and diaper) had the greatest risk $(\mathrm{RR}=4.2,95 \% \mathrm{CI}: 1.7$ 10.6).

\section{Discussion}

Analyzing data from a longitudinal cohort of 8314 SCI patients, we estimated that within 8 years post injury, approximately $6.8 \%$ would develop their first kidney stone. Although this figure is not significantly different than the previous report of $8.1 \%$ within 8 years in $1984,{ }^{5}$ this nonsignificant reduction in cumulative incidence (from $8.1 \%$ to $6.8 \%$ ) may be somewhat underestimated because the completeness of case ascertainment has been improved in this present study by rewording the question asking the presence of kidney/ureter stones as an obligate response (yes/no), rather than a voluntary response (open end) as before. Even so, the risk of kidney stones is still considerably higher compared with the general population where an annual incidence of 0.4 to 2.0 per 1000 population and a lifetime risk of $12 \%$ have been reported (Table 4). ${ }^{14-17}$

There is lack of comparable data from other countries or ethnic groups on the kidney stone

Table 3 Risk factors for kidney stones occurring before and after the first year post injury

\begin{tabular}{|c|c|c|c|c|c|c|c|c|}
\hline \multirow[b]{2}{*}{ Factor } & \multicolumn{4}{|c|}{ Year One } & \multicolumn{4}{|c|}{ Year 2 and Later } \\
\hline & $R R$ & $95 \% C I$ & $R R^{*}$ & $95 \% C I$ & $R R$ & $95 \% C I$ & $R R^{*}$ & $95 \% C I$ \\
\hline \multicolumn{9}{|l|}{ Gender } \\
\hline Women & 1.0 & & 1.0 & & 1.0 & & 1.0 & \\
\hline Men & 1.3 & $0.8-2.1$ & 1.5 & $0.9-2.5$ & 1.3 & $0.8-2.0$ & 1.4 & $0.9-2.2$ \\
\hline \multicolumn{9}{|l|}{ Race } \\
\hline African American & 1.0 & & 1.0 & & 1.0 & & 1.0 & \\
\hline Caucasian & 2.0 & $1.3-3.2$ & 2.1 & $1.3-3.3$ & 1.4 & $0.9-2.0$ & 1.3 & $0.8-1.9$ \\
\hline Hispanic & 1.0 & $0.5-2.1$ & 1.1 & $0.5-2.3$ & 0.6 & $0.3-1.4$ & 0.6 & $0.3-1.3$ \\
\hline Other & 2.6 & $1.1-6.3$ & 2.8 & $1.1-6.8$ & 1.0 & $0.3-3.3$ & 1.0 & $0.3-3.1$ \\
\hline \multicolumn{9}{|l|}{ Age $\dagger$ (years) } \\
\hline $15-24$ & 1.4 & $0.9-2.3$ & 1.5 & $0.9-2.3$ & 1.3 & $0.9-2.0$ & 1.3 & $0.8-2.0$ \\
\hline $25-34$ & 1.0 & & 1.0 & & 1.0 & & 1.0 & \\
\hline $35-44$ & 1.5 & $0.9-2.6$ & 1.5 & $0.9-2.6$ & 1.1 & $0.7-1.8$ & 1.1 & $0.7-1.8$ \\
\hline $45-54$ & 1.8 & $1.0-3.4$ & 1.8 & $1.0-3.5$ & 0.8 & $0.4-1.6$ & 0.9 & $0.4-1.7$ \\
\hline$>54$ & 2.0 & $1.2-3.6$ & 2.0 & $1.1-3.5$ & 1.3 & $0.8-2.3$ & 1.5 & $0.9-2.6$ \\
\hline \multicolumn{9}{|l|}{ Neurologic deficit } \\
\hline ASIA grade D & 1.0 & & 1.0 & & 1.0 & & 1.0 & \\
\hline Paraplegic, ASIA grade $\mathrm{A}, \mathrm{B}$, or $\mathrm{C}$ & 1.1 & $0.7-1.7$ & 1.1 & $0.6-1.9$ & 1.7 & $1.0-3.0$ & 1.4 & $0.8-2.7$ \\
\hline Tetraplegic, ASIA grade $\mathrm{A}, \mathrm{B}$, or $\mathrm{C}$ & 1.7 & $1.1-2.7$ & 1.6 & $1.0-2.8$ & 2.4 & $1.4-4.2$ & 1.9 & $1.0-3.6$ \\
\hline \multicolumn{9}{|l|}{ Bladder management $\dagger$} \\
\hline Catheter-free & 1.0 & & 1.0 & & 1.0 & & 1.0 & \\
\hline Indwelling urethral catheter & 1.9 & $1.0-3.5$ & 1.3 & $0.6-2.7$ & 3.3 & $1.5-7.2$ & 2.5 & $1.1-5.7$ \\
\hline Condom catheter & 1.7 & $0.8-3.5$ & 1.3 & $0.6-2.8$ & 2.8 & $1.3-6.1$ & 2.0 & $0.9-4.6$ \\
\hline Intermittent catheter & 1.4 & $0.8-2.3$ & 1.2 & $0.6-2.1$ & 3.1 & $1.5-6.1$ & 2.4 & $1.2-5.2$ \\
\hline Suprapubic catheter & 0.5 & $0.1-2.1$ & 0.3 & $0.1-1.3$ & 4.0 & $1.8-9.1$ & 2.6 & $1.1-6.3$ \\
\hline Other & 0.7 & $0.2-3.0$ & 0.6 & $0.1-2.6$ & 4.4 & $1.7-11.0$ & 4.2 & $1.7-10.6$ \\
\hline
\end{tabular}

Abbreviations: RR, risk ratio; CI, confidence interval. *Multivariable Cox regression models adjusted for other listed variables. $\dagger$ Time-variant measurements 
Table 4 Annual incidence of urinary stones in the general population

\begin{tabular}{|c|c|c|c|c|}
\hline Authors & $\begin{array}{l}\text { Study } \\
\text { period }\end{array}$ & $\begin{array}{l}\text { Design/ } \\
\text { location }\end{array}$ & Outcome & $\begin{array}{l}\text { Annual incidence } \\
\text { (per } 1000)\end{array}$ \\
\hline Johnson et $a l^{16}$ & $1950-74$ & $\begin{array}{l}\text { Longitudinal study, } \\
\text { Rochester, Minnesota }\end{array}$ & $\begin{array}{l}\text { First symptomatic kidney } \\
\text { stones }\end{array}$ & $0.69^{*}$ \\
\hline Hiatt et $a l^{15}$ & $1970-72$ & $\begin{array}{l}\text { Statewide survey, } \\
\text { San Francisco, California }\end{array}$ & $\begin{array}{l}\text { Outpatient diagnosis of new } \\
\text { or recurrent kidney or } \\
\text { ureter stones }\end{array}$ & $1.22 *$ \\
\hline Hiatt et $a l^{15}$ & $1971-75$ & $\begin{array}{l}\text { Survey in Northen } \\
\text { California, Kaiser } \\
\text { Foundation Health Plan }\end{array}$ & $\begin{array}{l}\text { Hospital discharge diagnosis } \\
\text { of kidney or ureter stones }\end{array}$ & $0.36^{*}$ \\
\hline Schappert $^{17}$ & 1993 & $\begin{array}{l}\text { National Health } \\
\text { Care Survey }\end{array}$ & $\begin{array}{l}\text { Outpatient diagnosis of } \\
\text { kidney or ureter stones }\end{array}$ & 2.00 \\
\hline Graves and Gillum ${ }^{14}$ & 1994 & $\begin{array}{l}\text { National Health } \\
\text { Care Survey }\end{array}$ & $\begin{array}{l}\text { Hospital discharge } \\
\text { diagnosis of kidney or } \\
\text { ureter stones }\end{array}$ & 0.81 \\
\hline
\end{tabular}

*Age adjusted incidence rate

incidence among SCI individuals. A recent study in Australia reported that kidney stones (first or recurrent) occurred to $3.5 \%$ of 1669 SCI patients between 1982 and $1996 .^{18}$ The rate was $0.3 \%$ in the first year of injury and $0.9 \%$ at 2 years, which appears to be smaller than our findings. However, this conclusion is limited because these data were not comparable regarding the subject eligibility (ie, newly injured or chronic), definition of stone disease (ie, first or recurrent), subject characteristics, length of followup, and analytic methods.

The pattern of decreasing nephrolithiasis risk with time post injury observed in this cohort is in agreement with the previous cohort. ${ }^{5}$ A peak stone incidence was observed during the first 3 months regardless of gender, race, and severity of injury (data not shown). Interestingly, the dysfunction of mineral metabolism such as hypercalciuria, which occurs at the acute phase of cord injury, seems to parallel and perhaps produce the peak incidence of stone formation. 19

During the first year post injury, when immobilization hypercalciuria is a concern, an increased risk of kidney stones in men, Caucasians, and people between 40 and 60 years of age is consistent with findings in the general population, ${ }^{15,16,20}$ where calcium stones are predominant. $^{21}$ The differential urinary excretion of calcium as a result of variation in hormones (such as testosterone) with age and gender has been hypothesized to account for the observed risk difference in the general population. The potential influence of these demographic factors on mineral metabolism during the acute phase of injury might explain the variation in stone risk, which needs further confirmation.

Similarly, an increased risk of stones among persons with more severe injury could be partly explained by a direct relation between the extent of injury and mineral metabolism dysfunction during the first year. ${ }^{19}$ The null relation between kidney stones and bladder management observed at this risk period is probably to some extent attributed to the fact that the majority of initially hospitalized SCI patients underwent intermittent catheterization, had better bladder care, or both. It might also suggest that there is no direct relation between type of urinary drainage and kidney stones that largely result from immobilization hypercalciuria.

The present finding that risk factors for stones somewhat varied within the two risk periods (before and after the first year) implies that different causal elements may be involved in the development of stones at the two different periods. In prior studies of chemical composition of SCI-related stones, the ratio of struvite to carbonate apatite tended to increase with increasing years post injury. ${ }^{1}$ As the content of struvite is thought to be an indicator of infection, urinary tract infection (UTI) appears to play a more important role in stone causation in later years.

After the first year post injury, the slightly increased risk (not statistically significant) in men and Caucasians is different from observations in the general population where struvite stones are more common in women $^{22}$ and African Americans. ${ }^{20}$ One possible explanation for this conflicting association with gender may be because the neurogenic bladder dysfunction and bladder management in male SCIs overcomes the effect of a shorter urethra, one prone to inflammation at the meatus in non-SCI women, on infection; therefore, the increased risk of struvite stones observed in the normal able-bodied women is eliminated in the SCI population. A potential selection bias from a differential rate of lost to follow-up between genders might also affect the validity of this finding. For instance, if healthier women are less likely to be lost, the observed higher risk in men than women would have been overestimated. Another discrepancy regarding the association between race and kidney stones is in a prospective study of 64 SCIs free of indwelling catheters. Waites et $a l^{23}$ reported that the incidence of UTI, a well-known predictor of SCI-related stones, was higher in African Americans than in Caucasians. A possible explanation is that in 
addition to UTI, race might be an indicator of other stone determinants such as microbiologic characteristics of infection, diet, fluid intake, and other host factors.

The impact of bladder management on stone formation has long been considered by clinicians, but not consistently supported by the medical literatures (Table 5). ${ }^{5,8-11,18,24}$ This analysis takes into account the time-variant nature of bladder management and thus probably provides risk estimates with least bias. This investigation adds to the evidence that people voiding satisfactorily with continent bladder control have a low stone risk. ${ }^{10,11}$ For other types of bladder drainage, including indwelling urethral or suprapubic, intermittent, and condom catheterization, the likelihood of developing stones seemed to be not significantly different $(P>0.35$ data not shown), which is supported by most previous findings. $5,8,10,24$

That the observed risk of kidney stones in persons using intermittent catheterization was equivalent to users of condom or indwelling catheters appears contrary to the reported relation between UTI and bladder management. ${ }^{23,25}$ The differential rate of lost to follow-up might partially explain this discrepancy. It is also possible that in addition to UTI, other risk factors for stones (such as fluid intake) play a part in the pathway connecting bladder management to stone formation.
Several limitations in this present study need to be considered while interpreting the results. The identified risk factors might not be specific for struvite stones because data on chemical composition of these diagnosed stones were not available. However, the significant association of stone formation with severity of injury and bladder management suggests that such misclassification, if any, is minimal. Similarly, we may have included stones that were present and not diagnosed before injury. However, given the low background rate of kidney stones in the general population, those are likely to represent only a very small proportion of the stones studied and their inclusion is unlikely to have much impact on measures of occurrence and association.

Another limitation is that these identified stone determinants might not be generalizable to persons with minimal deficit, lost to the health systems, and injured for more than 13 years, who are either underrepresentated or not covered by this study cohort. In other words, the observed kidney stone incidence among study participants might have overestimated the overall incidence in the SCI population because the Model Systems tend to treat more severe patients and persons with minimal deficit are likely to be lost. Similarly, the differential lost to follow-up rate might somewhat bias these risk estimates, particularly in later years, if the underlying risk of stones differs

Table 5 Methods of bladder management and the risk of kidney stones in persons with spinal cord injury

\begin{tabular}{|c|c|c|c|c|c|}
\hline Authors & $\begin{array}{l}\text { No. } \\
\text { SCI }\end{array}$ & $\begin{array}{l}\text { No. } \\
\text { Stones }\end{array}$ & $\begin{array}{l}\text { Years of } \\
\text { follow-up }\end{array}$ & $\begin{array}{l}\text { Methods of bladder } \\
\text { management under study }\end{array}$ & Findings \\
\hline \multirow[t]{2}{*}{ DeVivo et $a l^{5}$} & 5299 & & Initial hospitialization & & NS \\
\hline & 4214 & & 2 & $\begin{array}{l}\text { Foley, IC, condom, suprapubic, } \\
\text { crede manoeuvre }\end{array}$ & NS \\
\hline DeVivo et $a l^{8}$ & 125 & 25 & Matched* & $\begin{array}{l}\text { Foley, IC, condom, } \\
\text { crede manoeuvre, other }\end{array}$ & NS \\
\hline Kohli and Lamid ${ }^{10}$ & 36 & 12 & $\geqslant 5$ & $\begin{array}{l}\text { Foley, condom, suprapubic, } \\
\text { ileal conduit, good bladder } \\
\text { control }\end{array}$ & $\begin{array}{l}\text { Decreased risk in } \\
\text { people with good } \\
\text { bladder control; NS } \\
\text { between foley } \\
\text { and condom }\end{array}$ \\
\hline Hall et al ${ }^{9}$ & 898 & 198 & $\geqslant 2$ & $\begin{array}{l}\text { Indwelling catheter (urethral or } \\
\text { suprapubic), External appliance }\end{array}$ & $\begin{array}{l}\text { Increased risk in } \\
\text { people with } \\
\text { indwelling catheter }\end{array}$ \\
\hline Dewire et $a l^{24}$ & 57 & 14 & $\geqslant 10$ & $\begin{array}{l}\text { Indwelling catheter (urethral or } \\
\text { suprapubic), Non-catheterized } \\
\text { (IC, condom, urinary diversion, } \\
\text { spontaneous voiding) }\end{array}$ & NS \\
\hline Larsen et $a l^{11}$ & 142 & 24 & $\geqslant 7$ & $\begin{array}{l}\text { Indwelling catheter (urethral or } \\
\text { suprapubic), non-catheterized } \\
\text { (IC, condom, spontaneous } \\
\text { voiding) }\end{array}$ & $\begin{array}{l}\text { Increased risk in } \\
\text { people with } \\
\text { indwelling catheter }\end{array}$ \\
\hline $\begin{array}{l}\text { Donnellan and } \\
\text { Bolton }^{18}\end{array}$ & 1669 & 58 & Unknown & $\begin{array}{l}\text { Indwelling catheter, IC, } \\
\text { sphincterotomy, spontaneous } \\
\text { voiding, urinary diversion, } \\
\text { bladder augmentation }\end{array}$ & $\begin{array}{l}\text { More }(49 \%) \text { stone } \\
\text { cases with indwelling } \\
\text { catheter, fewer }(1 \%) \\
\text { with IC, no } \\
\text { comparison provided }\end{array}$ \\
\hline
\end{tabular}

Abbreviations: IC, intermittent catheter; NS, non-significant $(P>0.05)$. *Stone cases and stone-free controls were matched on years post injury 
between lost and compliant participants. Finally, because of constraints with the existing database, the present study was unable to address effects of other potential risk factors for stones (including UTI, bladder stones, and other urologic complications), which might interplay with these study factors on stone formation.

\section{Conclusions}

Despite the advances in acute care, early mobilization, and urologic rehabilitation, little progress has been made over the last 25 years in reducing stone risk in persons with SCI. This is disappointing and suggests further studies are required to identify the critical and potentially modifiable elements in the causal pathway and to establish an effective prophylactic intervention program. In addition, because the greatest incidence occurs soon after spinal injury, any strategy directed against stone formation should be commenced immediately after the onset of cord lesion, particularly for those at high risk.

Age, gender, race, and severity of injury, and neurogenic bladder dysfunction are shown to have an influence on stone formation. Further research is necessary to examine how these factors or factors associated with them determine the kidney stone risk. As type of urinary drainage does not appear to be an important predictor, the relative risk of stone formation is not necessarily a factor that should determine the decision on bladder management.

\section{Acknowledgements}

This work was supported in part by grant \#H133N5000996A from the National Institute on Disability and Rehabilitation Research, Office of Special Education and Rehabilitation Services, United States Department of Education, Washington DC.

\section{References}

1 Burr RG. Urinary calculi composition in patients with spinal cord lesions. Arch Phys Med Rehabil 1978; 59: 84-88.

2 Nikakhtar B et al. Urolithiasis in patients with spinal cord injury. Paraplegia 1981; 19: 363 - 366.

3 Comarr AE. A long-term survey of the incidence of renal calculosis in paraplegia. J Urol 1955; 74: 447-452.

4 Comarr AE, Kawaichi GK, Bors E. Renal calculosis of patients with traumatic cord lesions. J Urol 1962; 87: 647-656.

5 DeVivo MJ, Fine PR, Cutter GR, Maetz HM. The risk of renal calculi in spinal cord injury patients. J Urol 1984; 131: $857-860$.
6 Prather GC. Spinal cord injuries: calculi of the urinary tract. $J$ Urol 1947; 57: 1097-1104.

7 Tori JA, Kewalramani LS. Urolithiasis in children with spinal cord injury. Paraplegia 1978-79; 16: 357-365.

8 DeVivo MJ, Fine PR. Predicting renal calculus occurrence in spinal cord injury patients. Arch Phys Med Rehabil 1986; 67: $722-725$.

9 Hall MK, Hackler RH, Zampieri TA, Zampieri JB. Renal calculi in spinal cord-injured patient: association with reflux, bladder stones, and foley catheter drainage. Urology 1989; 34: 126-128.

10 Kohli A, Lamid S. Risk factors for renal stone formation in patients with spinal cord injury. Br J Urol 1986; 58: $588-591$.

11 Larsen LD, Chamberlin DA, Khonsari F, Ahlering TE. Retrospective analysis of urologic complications in male patients with spinal cord injury managed with and without indwelling urinary catheters. Urology 1997; 50: $418-422$.

12 Stover SL, DeVivo MJ, Go BK. History, implementation, and current status of the National Spinal Cord Injury Database. Arch Phys Med Rehabil 1999; 80: $1365-1371$.

13 Callas PW, Pastides H, Hosmer DW. Empirical comparisons of proportional hazards, Poisson, and logistic regression modelling of occupational cohort data. Am J Ind Med 1998; 33: 33-47.

14 Graves EJ, Gillum BS. National hospital discharge survey: annual summary, 1994. Vital and Health Statistics. Series 10, No. 128, DHHS Publication No. 97-1789. Hyattsville, MD: National Center for Health Statistics, 1997.

15 Hiatt RA, Dales LG, Friedman GD, Hunkeler EM. Frequency of urolithiasis in a prepaid medical care program. Am J Epidemiol 1982; 115: $255-265$.

16 Johnson CM et al. Renal stone epidemiology: a 25-year study in Rochester, Minnesota. Kidney Int 1979; 16: 624-631.

17 Schappert SM. Ambulatory care visits to physician offices, hospital outpatient departments, and emergency departments: United States, 1995. Vital and Health Statistics. Series 13, No. 129, DHHS Publication No. 97-1790. Hyattsville, MD: National Center for Health Statistics, 1997.

18 Donnellan SM, Bolton DM. The impact of contemporary bladder management techniques on struvite calculi associated with spinal cord injury. BJU Int 1999; 84: 280-285.

19 Naftchi NE, Viau AT, Sell GH, Lowman EW. Mineral metabolism in spinal cord injury. Arch Phys Med Rehabil 1980; 61: $139-142$

20 Sarmina I, Spirnak JP, Resnick MI. Urinary lithiasis in the black population: an epidemiological study and review of the literature. J Urol 1987; 138: 14-17.

21 Leusmann DB, Blaschke R, Schmandt W. Results of 5035 stone analyses: a contribution to epidemiology of urinary stone disease. Scand J Urol Nephrol 1990; 24: 205-210.

22 Cohen TD, Preminger GM. Struvite calculi. Seminars in Nephrol 1996; 16: $425-434$.

23 Waites KB, Canupp KC, DeVivo MJ. Epidemiology and risk factors for urinary tract infection following spinal cord injury. Arch Phys Med Rehabil 1993; 74: 691 - 695.

24 Dewire EM et al. A comparison of the urological complications associated with long-term management of quadriplegics with and without chronic indwelling urinary catheters. J Urol 1992; 147: $1069-1072$.

25 Waites $\mathrm{KB}$ et al. Antimicrobial resistance in gram-negative bacteria isolated from the urinary tract in community-residing persons with spinal cord injury. Arch Phys Med Rehabil in press. 